\title{
The Impact of Jumps and Leverage in Forecasting Co-Volatility
}

Complutense

de Análisis Económico

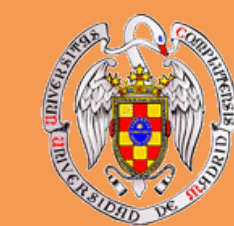

UNIVERSIDAD

COMPLUTENSE

MADRID

\author{
Manabu Asai \\ Faculty of Economics \\ Soka University, Japan
}

\section{Michael McAleer}

Department of Quantitative Finance

National Tsing Hua University Taiwan

and

Econometric Institute Erasmus School of Economics

Erasmus University Rotterdam

and

Tinbergen Institute The Netherlands

and

Department of Quantitative Economics

Complutense University of Madrid

\begin{abstract}
The paper investigates the impact of jumps in forecasting co-volatility, accommodating leverage effects. We modify the jump-robust two time scale covariance estimator of Boudt and Zhang (2013) such that the estimated matrix is positive definite. Using this approach we can disentangle the estimates of the integrated co-volatility matrix and jump variations from the quadratic covariation matrix. Empirical results for three stocks traded on the New York Stock Exchange indicate that the co-jumps of two assets have a significant impact on future co-volatility, but that the impact is negligible for forecasting weekly and monthly horizons.
\end{abstract}

Keywords Co-Volatility; Forecasting; Jump; Leverage Effects; Realized Covariance; Threshold Estimation.

JL Classification C C32, C53, C58, G17.

\section{Working Paper no 1502}

February, 2015 


\title{
The Impact of Jumps and Leverage in Forecasting Co-Volatility*
}

\author{
Manabu Asai \\ Faculty of Economics \\ Soka University, Japan \\ Michael McAleer \\ Department of Quantitative Finance \\ National Tsing Hua University, Taiwan \\ and \\ Econometric Institute \\ Erasmus School of Economics \\ Erasmus University Rotterdam \\ and \\ Tinbergen Institute \\ The Netherlands \\ and \\ Department of Quantitative Economics \\ Complutense University of Madrid, Spain
}

February 2015

\footnotetext{
${ }^{*}$ The authors are most grateful to Yoshi Baba and Karen Lewis for very helpful comments and suggestions. The first author acknowledges the financial support of the Japan Ministry of Education, Culture, Sports, Science and Technology, Japan Society for the Promotion of Science, and Australian Academy of Science. The second author is most grateful for the financial support of the Australian Research Council, National Science Council, Taiwan, and the Japan Society for the Promotion of Science. Address for correspondence: Faculty of Economics, Soka University, 1-236 Tangi-machi, Hachioji, Tokyo 192-8577, Japan. Email address: m-asai@soka.ac.jp.
} 


\begin{abstract}
The paper investigates the impact of jumps in forecasting co-volatility, accommodating leverage effects. We modify the jump-robust two time scale covariance estimator of Boudt and Zhang (2013) such that the estimated matrix is positive definite. Using this approach we can disentangle the estimates of the integrated co-volatility matrix and jump variations from the quadratic covariation matrix. Empirical results for three stocks traded on the New York Stock Exchange indicate that the co-jumps of two assets have a significant impact on future co-volatility, but that the impact is negligible for forecasting weekly and monthly horizons.
\end{abstract}

Keywords: Co-Volatility; Forecasting; Jump; Leverage Effects; Realized Covariance; Threshold Estimation.

JEL classifications: C32, C53, C58, G17. 


\section{Introduction}

Discontinuities, or jumps, in financial asset price movements are supported by recent empirical evidence in Bates (2000), Andersen et al. (2002), Pan (2002), Chernov et al. (2003), Eraker et al. (2003) and Eraker (2004), among others. There has also been growing interest in examining the effects of jumps on forecasting volatilities, accompanied by theoretical developments on nonparametric estimation of daily volatility via intraday data of financial asset prices.

Barndorff-Nielsen and Shephard (2004a) disentangled the jump components using the differences in the realized measures of quadratic and bipower variations. Huang and Tauchen (2005) and Andersen et al. (2007) report empirical evidence in support of non-trivial contributions to the daily price variation produced by jump components. Andersen et al. (2007) also developed volatility forecasting models using the jump components, and Corsi et al. (2010) made important contributions using threshold bipower variation. Bollerslev et al. (2009) used logarithmic jumps, and examined the effects of jumps by accommodating leverage effects. The empirical results of these papers indicate that jumps have a positive and mostly significant impact on future volatility (see also the useful survey of Aït-Sahalia and Jacod (2012)).

The purpose of the paper is to extend the contributions of Andersen et al. (2007) and Corsi et al. (2010) using realized co-volatility measures. There are several estimators of integrated co-volatilities, including Barndorff-Nielsen and Shephard (2004b), Hayashi and Yoshida (2005), Barndorff-Nielsen et al. (2011), Zhang (2011), Boudt et al. (2011, 2012), Hautsch et al. (2012), and Boudt and Zhang (2013), among others. The conditions for nonparametric estimation of co-movements via intraday data are: (i) robustness to jumps; (ii) robustness to microstructure noise caused by, for example, the bid-ask bounce; (iii) ability to handle asynchronicity of the times at which transactions are recorded; and (iv) the estimated covariance matrix is positive definite.

Of the above contributions, three papers satisfy three of the four conditions. The estimator of Barndorff-Nielsen et al. (2011) satisfies conditions (i), (ii) and (iv), Boudt et al. (2012) accommodate conditions (i), (iii), and (iv), while Boudt and Zhang (2013) incorporate conditions (i)-(iii). In this paper, we modify the estimator of Boudt and Zhang (2013) to incorporate condition (iv). Using the difference between the estimators of quadratic covariation and integrated covolatility, we obtain the estimator of jump variations. Based on the new estimator, we examine the impact of jumps and leverage on forecasting co-volatility. 
The remainder of the paper is organized as follows. Section 2 explains the approach to disentangling jump variations and integrated co-volatilities from the realized quadratic co-variation. Section 3 provides an empirical example for three stocks traded on the New York Stock Exchange, and shows that the 'co-jumps' and 'co-leverage' of any two assets have a significant impact on future co-volatility. Finally, Section 4 gives some concluding remarks.

\section{Theoretical Framework}

\section{$2.1 \quad$ Model Specification}

Let $p^{*}(s)$ denote a $q$-dimensional latent $\log$-price vector at time $s$, and $W(s)$ and $Q(s)$ denote $q$-vectors of independent Brownian motions and counting processes, respectively. Let $K(s)$ be the $q \times q$ process controlling the magnitude and transmission of jumps, such that $K(s) d Q(s)$ is the contribution of the jump process to the price diffusion. Under the assumption of a Brownian semimartingale with finite-activity jumps (BSMFAJ), $p^{*}(s)$ follows:

$$
d p^{*}(s)=\mu(s) d s+\sigma(s) d W(s)+K(s) d Q(s), \quad 0 \leq s \leq T
$$

where $\mu(s)$ is a $q$-dimensional vector of continuous and locally-bounded variation processes, and $\sigma(s)$ is the $q \times q$ matrix, such that $\Sigma(s)=\sigma(s) \sigma^{\prime}(s)$ is positive definite.

Assume that the observable log-price process is the sum of the latent log-price process in equation (1) and the microstructure noise process. For $q=2$, define the log-price process as $p(s)=\left(X_{s}, Y_{s}\right)$. Consider non-synchronized trading times of the two assets, and let $\mathcal{T}$ and $\Theta$ be the set of transaction times of $X$ and $Y$, respectively. Denote the counting process governing the number of observations traded in assets $X$ and $Y$ up to time $t$ as $n_{t}$ and $m_{t}$, respectively. By definition, the trades in $X$ and $Y$ occur at times $\mathcal{T}=\left\{\tau_{1}, \tau_{2}, \ldots, \tau_{n_{T}}\right\}$ and $\Theta=\left\{\theta_{1}, \theta_{2}, \ldots, \theta_{m_{T}}\right\}$. For convenience, the opening and closing times are set as $\tau_{1}=\theta_{1}=0$ and $\tau_{n_{T}}=\theta_{m_{T}}=T$, respectively.

The observable log-price process is given by:

$$
X_{\tau_{i}}=X_{\tau_{i}}^{*}+\varepsilon_{\tau_{i}}^{X} \quad \text { and } \quad Y_{\theta_{j}}=Y_{\theta_{j}}^{*}+\varepsilon_{\theta_{j}}^{Y},
$$

where $\varepsilon^{X} \sim \operatorname{iid}\left(0, \sigma_{\varepsilon X}^{2}\right), \varepsilon^{Y} \sim \operatorname{iid}\left(0, \sigma_{\varepsilon Y}^{2}\right)$, and $\left(\varepsilon^{X}, \varepsilon^{Y}\right)$ are independent of $(X, Y)$.

Define the quadratic covariation (QCov) of the log-price process over $[0, T]$ as:

$$
\mathrm{QCov}=\operatorname{plim}_{\Delta \rightarrow \infty} \sum_{i=1}^{\lfloor T / \Delta\rfloor}[p(i \Delta)-p((i-1) \Delta)][p(i \Delta)-p((i-1) \Delta)]^{\prime} .
$$


Then we obtain

$$
\mathrm{QCov}=\int_{0}^{T} \Sigma(s) d s+\sum_{0<s \leq T} K(s) K^{\prime}(s) .
$$

The first term on the right-hand side of (4) is the integrated co-volatility (ICov) matrix over $[0, T]$, while the second term is the matrix of jump variability. We are interested in disentangling these two components from the estimates of QCov for the purpose of forecasting QCov.

We explain below the robust estimation of the integrated co-volatility matrix suggested by Boudt and Zhang (2013), under jumps and microstructure noise for the bivariate process in (2). First, we consider the $q$-variate case which consists of the estimators of integrated volatility and co-volatility, obtained using the approach of Boudt and Zhang (2013). Denote the estimators of

QCov, ICov and jump component at day $t$ as $\hat{\Omega}_{t}, \hat{C}_{t}$ and $\hat{J}_{t}$, respectively, where $\hat{J}_{t}=\hat{\Omega}_{t}-\hat{C}_{t}$. By the definitions in (1)-(4), the estimators should be positive (semi-) definite. One approach is to regularize the estimated covariance matrix by thresholding.

Bickel and Levina (2008a, b) and Tao et al. (2011) showed consistency of the regularized estimator, assuming a sparsity structure. Define the thresholding operator for a $q \times q$ matrix $A$ as:

$$
\mathbb{T}_{h}(A)=\left[a_{i j} \mathbf{1}\left(\left|a_{i j}\right| \geq h\right)\right]
$$

which can be regarded as $A$ thresholded at $h$. Define the Frobenius norm by $\|A\|_{F}^{2}=\operatorname{tr}\left(A A^{\prime}\right)$. For the selection of $h$, we follow Bickel and Levina (2008b). In order to obtain $\tilde{A}=\mathbb{T}_{h}(\hat{A})$, we minimize the distance by the Frobenius norm $\left\|\mathbb{T}_{h}(\hat{A})-\hat{A}\right\|_{F}^{2}$, with the restriction that $\tilde{A}$ is positive semi-definite. Using this approach, we obtain $\tilde{C}_{t}=\mathbb{T}_{h}\left(\hat{C}_{t}\right)$ and $\tilde{J}_{t}=\mathbb{T}_{h}\left(\hat{J}_{t}\right)$, which are consistent and positive semi-definite. Note that $\hat{\Omega}_{t}$ is generally positive definite, as it can be obtained by the sample analogue of QCov.

\subsection{Jump-Robust TSRV Estimator for Integrated Volatility}

Boudt and Zhang (2013) suggested a jump-robust estimator based on the two time scale realized volatility (TSRV) estimator of Zhang et al. (2005). Let $n$ be the total number of returns within $[0, T]$, with the price process observed at the time points $0=t_{1}<t_{2}<\cdots<t_{n+1}=T$. The standard realized volatility calculated on the whole data set is given as:

$$
[X, X]_{T}^{(\text {all })}=\sum_{i=1}^{n}\left(X_{t_{i+1}}-X_{t_{i}}\right)^{2} .
$$


We will shortly review the TSRV estimator in order to explain the jump robust estimator of Boudt and Zhang (2013).

The TSRV estimator is based on partitioning the whole sample into $K$ subsamples. Let $\mathcal{G}$ denote the full grid $\mathcal{G}=\left\{t_{0}, \ldots, t_{n+1}\right\}$, consider the subgrid $\mathcal{G}^{(k)}$, which starts with $t_{k-1}$, and select every $K$ th sample point after that, until $T$. Thus,

$$
\mathcal{G}^{(k)}=\left\{t_{k-1}, t_{k-1+K}, t_{k-1+2 K}, \ldots, t_{k-1+n_{k} K}\right\}, \quad \text { for } k=1, \ldots, K,
$$

where $n_{k}$ is the integer making $t_{k-1+n_{k} K}$ the last element in $\mathcal{G}^{(k)}$, such that

$$
\mathcal{G}=\bigcup_{k=1}^{K} \mathcal{G}^{(k)}, \quad \text { with } \mathcal{G}^{(k)} \bigcap \mathcal{G}^{(l)}=\emptyset \text { when } k \neq l .
$$

The realized volatility for the subsampled observations is denoted by:

$$
[X, X]_{T}^{(k)}=\sum_{t_{j}, t_{j+K} \in \mathcal{G}^{(k)}}\left(X_{t_{j+K}}-X_{t_{j}}\right)^{2}
$$

The averaged realized volatility is defined by

$$
[X, X]_{T}^{(\operatorname{avg}, K)}=\frac{1}{K} \sum_{k=1}^{K}[X, X]_{T}^{(k)} .
$$

The TSRV estimator of Zhang et al. (2005) is defined as the difference between the averaged realized volatility computed over $K$ steps apart subsampled observations and the adjusted realized volatility computed using all the observations.

The TSRV estimator modified by Aït-Sahalia et al. (2011) is given as:

$$
\operatorname{TSRV}=\left(1-\frac{\bar{n}_{K}}{\bar{n}_{J}}\right)^{-1}\left([X, X]_{T}^{(\mathrm{avg}, K)}-\frac{\bar{n}_{K}}{\bar{n}_{J}}[X, X]_{T}^{(\mathrm{avg}, J)}\right),
$$

where $K>J, \bar{n}_{K}=\sum_{k=1}^{K} n_{k}=(n-K+1) / K$, and $[X, X]_{T}^{(\operatorname{avg}, J)}$ and $\bar{n}_{J}$ are defined analogously. If $j=1$, the above estimator reduces to the original estimator of Zhang et al. (2005). The estimate of the noise variance is given by:

$$
\hat{\sigma}_{\varepsilon X}^{2}=\frac{1}{2 \bar{n}_{J}}\left([X, X]_{T}^{(\operatorname{avg}, J)}-\mathrm{TSRV}\right),
$$

which will be used later in this subsection. 
Boudt and Zhang (2013) suggested a jump-robust TSRV (RTSRV) estimator as a mixture of the TSRV estimator in (6), and the truncated realized volatility estimators of Macini and Renó (2011) and Boudt et al. (2011). Define the indicator function as:

$$
I_{X}^{K}(i ; u)=\left\{\begin{array}{cc}
1, & \text { if } \frac{\left(X_{t_{i+K}}-X_{t_{i}}\right)^{2}}{\left(\int_{t_{i}}^{t_{i}+K} \sigma_{t}^{2} d t+\sigma_{\varepsilon X}^{2}\right)} \leq u \\
0, & \text { otherwise }
\end{array}\right.
$$

Note that $\int_{t_{i}}^{t_{i}+K} \sigma_{t}^{2} d t+\sigma_{\varepsilon X}^{2}$ is the variance of $X_{t_{i+K}}-X_{t_{i}}$. Thus, the truncated realized volatility based on $K$-step apart returns and the average realized volatility are given by:

$$
\begin{aligned}
& \{X, X\}_{T}^{(k)}=\frac{c_{u}^{*} n_{k} \sum_{\left\{t_{j}, t_{j+K} \in \mathcal{G}^{(k)}\right\}}\left(X_{t_{j+K}}-X_{t_{j}}\right)^{2} I_{X}^{K}(i ; u)}{\sum_{\left\{t_{j}, t_{j+K} \in \mathcal{G}^{(k)}\right\}} I_{X}^{K}(i ; u)}, \\
& \{X, X\}_{T}^{(\operatorname{avg}, K)}=\frac{1}{K} \sum_{k=1}^{K}\{X, X\}_{T}^{(k)},
\end{aligned}
$$

respectively, where the factor $c_{u}^{*}=F_{\chi_{1}^{2}}(u) / F_{\chi_{3}^{2}}(u)$ is a constant to adjust for the bias due to the thresholding, and $F_{\chi_{v}^{2}}$ is the chi-squared distribution function with $v$ degrees of freedom, with $\{X, X\}_{T}^{(\operatorname{avg}, J)}$ defined analogously. Boudt and Zhang (2013) uses $u=9$, which corresponds to truncating returns that are greater than three standard deviations from the mean of the normal distribution.

Boudt and Zhang (2013) defined the RTSRV estimator as the difference between the truncated realized volatility on $K$-step and $J$-step apart returns, that is:

$$
\operatorname{RTSRV}=\left(1-\frac{\bar{n}_{K}}{\bar{n}_{J}}\right)^{-1}\left(\{X, X\}_{T}^{(\operatorname{avg}, K)}-\frac{\bar{n}_{K}}{\bar{n}_{J}}\{X, X\}_{T}^{(\operatorname{avg}, J)}\right) .
$$

As in practice we need to estimate the variance of $X_{t_{i+K}}-X_{t_{i}}$ in order to calculate the indicator function, we follow the approach of Boudt and Zhang (2013). Equation (7) is used to estimate the variance of the noise, while the estimation of $\int_{t_{i}}^{t_{i+K}} \sigma_{s}^{2} d s$ uses the approximation:

$$
\int_{t_{i}}^{t_{i+K}} \sigma_{s}^{2} d s \approx \frac{t_{i+K}-t_{i}}{T} \widehat{\int_{t_{i}}^{T} \sigma_{s}^{2}} d s
$$

which is valid if the intraday volatility is highly persistent. For the estimation of $\int_{t_{i}}^{T} \sigma_{s}^{2} d s$, Boudt and Zhang (2013) used an iterative approach. They used the medRV estimator of Andersen et al. (2012) to obtain the initial value for the computation of the RTSRV estimate in equation (9), then iterated the new RTSRV estimate to compute the threshold until no large returns require further truncation. 
For the choice of $K$ and $J$, Aït-Sahalia et al. (2011) recommended a choice corresponding to $K$ to 5 minute and $J$ to 1 minute for the TSRV estimator. The simulation results of Boudt and Zhang (2013) suggest that the RTSRV estimator generally yields smaller relative bias and RMSE than the bipower variation of Barndorff-Nielsen and Shepard (2004a), the medRV estimator of Andersen et al. (2012), and the threshold bipower variation of Corsi et al. (2010), under the existence of jumps and microstructure noise.

\subsection{Jump-Robust TSCV Estimator for Integrated Co-Volatility}

Boudt and Zhang (2013) also developed a jump-robust estimator using the two time scale realized co-volatility (TSRC) estimator of Zhang (2011), extending the idea of RTSRV. We start from the non-synchronicity in trading times of the two assets, and let $\mathcal{T}$ and $\Theta$ be the set of transaction times of $X$ and $Y$, respectively. Denote the counting process governing the number of observations traded in assets $X$ and $Y$ up to time $t$ as $n_{t}$ and $m_{t}$, respectively. By definition, the trades in $X$ and $Y$ occur at the times $\mathcal{T}=\left\{\tau_{1}, \tau_{2}, \ldots, \tau_{n_{T}}\right\}$ and $\Theta=\left\{\theta_{1}, \theta_{2}, \ldots, \theta_{m_{T}}\right\}$, respectively. We specify the opening and closing time as $\tau_{1}=\theta_{1}=0$ and $\tau_{n_{T}}=\theta_{m_{T}}=T$, for convenience.

The refresh time method selects the so-called refresh times at which all assets have traded at least once since the last refresh time point. Let $N=n_{T}+m_{T}+2$. After the opening time, $\nu_{1}=\tau_{1}=$ $\theta_{1}$, the subsequent refresh time is defined as the first time when both stocks have traded, namely $\nu_{j+1}=\max \left(\tau_{n_{\nu_{j}}+1}, \theta_{m_{\nu_{j}}+1}\right)$. The whole refresh time sample grid is $\mathcal{V}=\left\{\nu_{1}, \nu_{2}, \ldots, \nu_{M_{N}+1}\right\}$, where $M_{N}$ is the number of paired returns. Under the previous tick approach, the sampling points of assets $X$ and $Y$ are defined as $t_{i}=\max \left\{\tau \in \mathcal{T}: \tau \leq \nu_{i}\right\}$ and $s_{i}=\max \left\{\theta \in \Theta: \theta \leq \nu_{i}\right\}$, respectively.

Based on the refresh time grid, the previous tick estimator for co-volatility is defined by:

$$
[X, Y]_{T}=\sum_{i=1}^{M_{N}}\left(X_{t_{i+1}}-X_{t_{i}}\right)\left(Y_{s_{i+1}}-X_{s_{i}}\right) .
$$

As before, define the subgrid $\mathcal{V}^{(k)}$ for $\mathcal{V}$, then the estimator for the subsampled observations is given by:

$$
[X, Y]_{T}^{(k)}=\sum_{\nu_{j}, \nu_{j+K} \in \mathcal{V}_{\tau}^{(k)}}\left(X_{t_{j+K}}-X_{t_{j}}\right)\left(Y_{s_{j+K}}-Y_{s_{j}}\right)
$$

where the relations among $t_{j}, s_{j}$ and $\tau_{j}$ are defined as before. Then we obtain the averaged 
realized co-volatility estimator as:

$$
[X, Y]_{T}^{(\operatorname{avg}, K)}=\frac{1}{K} \sum_{k=1}^{K}[X, Y]_{T}^{(k)} .
$$

In order to remove the possible dependence between microstructure noise on $X$ and $Y$, Zhang (2011) developed the TSRC estimator as:

$$
\operatorname{TSCV}=c_{N}\left([X, Y]_{T}^{(\operatorname{avg}, K)}-\frac{\bar{n}_{K}}{\bar{n}_{J}}[X, Y]_{T}^{(\operatorname{avg}, J)}\right),
$$

where $\bar{n}_{K}=\left(M_{N}-K+1\right) / K, \bar{n}_{J}=\left(M_{N}-J+1\right) / K$ and $c_{N}=M_{N} /\left((K-J) \bar{n}_{K}\right)$.

Boudt and Zhang (2013) suggested a jump-robust TSRC (RTSRC) estimator using the indicator functions $I_{X}^{K}(i ; u)$ and $I_{Y}^{K}(i ; u)$ defined in (8), based on the TSRC estimator in (10). The truncated realized co-volatility on $K$-step apart returns and the average realized co-volatility are given by:

$$
\begin{aligned}
& \{X, Y\}_{T}^{(k)}=\frac{c_{i} n_{k} \sum_{\left\{v_{j}, v_{j+K} \in \mathcal{V}^{(k)}\right\}}\left(X_{t_{j+K}}-X_{t_{j}}\right)\left(Y_{s_{j+K}}-Y_{s_{j}}\right) I_{X}^{K}(i ; u) I_{Y}^{K}(i ; u)}{\sum_{\left\{v_{j}, v_{j+K} \in \mathcal{V}^{(k)}\right\}} I_{X}^{K}(i ; u) I_{Y}^{K}(i ; u)}, \\
& \{X, Y\}_{T}^{(\mathrm{avg}, K)}=\frac{1}{K} \sum_{k=1}^{K}\{X, Y\}_{T}^{(k)},
\end{aligned}
$$

where $c_{i}$ is the correction factor, which is specified as $c_{i}=1.042$ in Boudt and Zhang (2013), and $\{X, Y\}_{T}^{(\operatorname{avg}, J)}$ is defined analogously. Boudt and Zhang (2013) defined the RTSCV estimator as the difference between the truncated realized co-volatility on $K$-step and $J$-step apart returns, namely:

$$
\mathrm{RTSRC}=c_{N}\left(\{X, Y\}_{T}^{(\operatorname{avg}, K)}-\frac{\bar{n}_{K}}{\bar{n}_{J}}\{X, Y\}_{T}^{(\operatorname{avg}, J)}\right)
$$

Using estimation techniques for RTSRV (9) and RTSRC (11), we can construct the robust estimator of the $q \times q$ integrated co-volatility matrix at day $t, \hat{C}_{t}$, under jumps and microstrucutre noise. We can also obtain the estimator of QCov, which we denote as $\hat{\Omega}_{t}$, by using $[X, X]_{T}^{\text {all }}$ and $[X, Y]_{T}$, which leads to the jump estimator $\hat{J}_{t}=\hat{\Omega}_{t}-\hat{C}_{t}$. Applying the threshold operator defined by (5), we obtain the final estimates as $\tilde{C}_{t}=\mathbb{T}_{h}\left(\hat{C}_{t}\right)$ and $\tilde{J}_{t}=\mathbb{T}_{h}\left(\hat{J}_{t}\right)$.

\section{Empirical Analysis}

We examine the effects on jumps and leverage on forecasting co-volatility, using the estimates of the QCov, ICov and jump variation, for three stocks traded on the New York Stock Exchange, 
namely Alcoa Inc. (AA), American Express (AXP), and Bank of America (BAC). Based on the vector of returns for the $q=3$ stocks computed for a 1-minute interval of trading day at t between 9:30 am and 4:00 pm. We calculated the daily values of $\hat{\Omega}_{t}, \tilde{C}_{t}$ and $\tilde{J}_{t}$, as explained in the previous section, and also calculated the corresponding open-close returns for the three assets. The sample period starts at August 31, 2006, and ends on October 26, 2012, giving 1500 observations.

The sample is divided into two periods. The first 500 observations cover the period until September 12, 2008, while the latter period starts from the bankruptcy of Lehman Brothers, that is, September 15, 2008, giving 1000 observations, which are used for evaluating the out-of-sample forecasts.

Table 1 presents the descriptive statistics of the returns, $r_{t}$, and estimated QCov, $\hat{\Omega}_{t}$. The empirical distribution of the returns is heavily skewed to the left and is highly leptokurtic. Regarding volatility and co-volatility, they are skewed to the right, with evidence of heavy-tails in all the series. It should be noted that extremely large values for the volatilities are observed during the Global Financial Crisis (GFC). Figure 1 shows significant jump variability, indicating that jump variabilities are high in the period of turbulence caused by the GFC.

In order to examine the impact of jumps and leverage for forecasting volatility and co-volatility, we use three kinds of heterogeneous autoregression (HAR) type models for forecasting $(i, j)$ element of $\hat{\Omega}_{t-h: t}(h=1,5,22)$, as follows:

$$
\begin{aligned}
& \hat{\Omega}_{i j, t}=\beta_{0}+\beta_{d} \hat{\Omega}_{i j, t-1}+\beta_{w} \hat{\Omega}_{i j, t-5: t-1}+\beta_{m} \hat{\Omega}_{i j, t-22: t-1}+u_{i j, t} \\
& \hat{\Omega}_{i j, t}=\beta_{0}+\beta_{d} \tilde{C}_{i j, t-1}+\beta_{w} \tilde{C}_{i j, t-5: t-1}+\beta_{m} \tilde{C}_{i j, t-22: t-1}+\beta_{j} \tilde{J}_{i j, t-1}+u_{i j, t} \\
& \hat{\Omega}_{i j, t}=\beta_{0}+\beta_{d} \tilde{C}_{i j, t-1}+\beta_{w} \tilde{C}_{i j, t-5: t-1}+\beta_{m} \tilde{C}_{i j, t-22: t-1}+\beta_{j} \tilde{J}_{i j, t-1}+\beta_{a} r_{i, t-1}^{-} r_{j, t-1}^{-}+u_{i j, t},
\end{aligned}
$$

where $r_{i, t}^{-}=r_{i, t} I\left(r_{i, t}<0\right)$, which is the negative part of the return of the $i$-th asset. In the second model, we use the previous values of the estimated continuous sample path component variation, $\tilde{C}_{t}$, rather than those of estimated quadratic variation, $\hat{\Omega}_{t}$, following the volatility forecasting models of Andersen et al. (2007) and Corsi et al. (2010). We exclude weekly and monthly effects of the jump component, $\tilde{J}_{t}$, in order to evaluate the impact of a single jump on future volatility and co-volatility. Note that $\tilde{C}_{t}$ and $\tilde{J}_{t}$ are positive (semi-) definite by the thresholding in (5). In addition to jump variability, the third model includes the asymmetric effect, as in the specification of the asymmetric BEKK model of Kroner and $\mathrm{Ng}$ (1998). For $i \neq j, \beta_{a} r_{i, t-1}^{-} r_{j, t-1}^{-}$represents the 'co-leverage' effect which is caused by simultaneous negative returns of two assets. We refer 
to equations (12), (13) and (14) as the HAR, HAR-TCJ and HAR-TCJA models, respectively. Although the estimate of $\beta_{j}$ and $\beta_{a}$ are expected to be positive and significant for the volatility equation $(i=j)$, their signs are not determined for the co-volatility equation $(i \neq j)$.

We estimate each model using the first 500 observations, and obtain a forecast, $\hat{\Omega}_{501}^{f}$ We reestimate each model fixing the sample size at 500, and obtain new forecasts based on updated parameter estimates. For evaluating the forecasting performance of the different models, we report the $R^{2}$ of the Mincer-Zarnowitz (MZ) regression, namely

$$
\hat{\Omega}_{i j, t}=\alpha_{0}+\alpha_{1} \hat{\Omega}_{i j, t}^{f}+\text { error }, \quad t=501, \ldots, 1500
$$

We also use the heteroskedasticity-adjusted root mean square error suggested in Bollerslev and Ghysels (1996), namely:

$$
\operatorname{HRMSE}=\sqrt{\frac{1}{1000} \sum_{t=501}^{1500}\left(\frac{\hat{\Omega}_{i j, t}-\hat{\Omega}_{i j, t}^{f}}{\hat{\Omega}_{i j, t}}\right)^{2}}
$$

For the latter, we examine equal forecast accuracy using the Diebold and Mariano (1995) test at the $5 \%$ significance level, and use the heteroskedasticity and autocorrelation consistent (HAC) covariance matrix estimator, with bandwidth 25 .

Table 2 shows the estimates of the daily regressions for the first 500 observations. The estimates of the jump parameter, $\beta_{j}$, are positive and significant, except for the co-volatility of AA and AXP. The results for volatilities support the empirical analysis of Andersen et al. (2007) and Corsi et al. (2010). The estimates of the coefficient of the asymmetric effect, $\beta_{a}$, are positive and significant for all cases, supporting that the negative relationship between return and future volatility. The results also imply that a pair of negative returns of two assets increase future co-volatility. The HAR-TCJA model gives the highest $\bar{R}^{2}$ in all cases. Table 3 presents $R^{2}$ of the MZ regressions and HRMSE for the daily regressions. The HAR-TCJA is the best model for forecasting volatility, while there are no significant differences for three models of the co-volatility equation. There is no obvious pastern for the difference between the results conditional on a previous jump and no jump.

Table 4 reports the estimates of the weekly regressions. The estimates of the jump parameter, $\beta_{j}$, and the parameter of the asymmetric effect, $\beta_{a}$, are positive and significant. Unlike the daily regressions, the HAR model gives the highest $\bar{R}^{2}$ values in all six cases. Table 5 gives the $R^{2}$ values of the MZ regressions, and HRMSE for the out-of-sample forecasts for the weekly regressions. 
Table 5 indicates that the values of $R^{2}$ are higher than those for the daily regressions in Table 3. Of the six cases, the HAR model is the best in three cases, while there are insignificant differences in the models for the remaining three cases. We may improve the forecasts by incorporating weekly and monthly effects of jumps and leverages.

Table 6 shows the in-sample estimates of the monthly regressions, while Table 7 reports the results of the corresponding out-of-sample forecasts. Tables 6 and 7 indicate that the results for the monthly regressions are similar to those of the weekly regressions.

The empirical results for the volatility models support the findings of Andersen et al. (2007) and Corsi et al. (2010). Regarding the co-volatility, the impacts of co-jumps of two assets are generally positive and significant for the daily, weekly, and monthly regressions. Although the HAR-TCJ model performs better than the HAR model for the daily regressions, the three models produce broadly similar results for the weekly and monthly regressions. The asymmetric effects are generally positive and significant for both volatility and co-volatility equations, supporting the empirical results in the literature. We can improve the HAR-TCJ and HAR-TCJA models, by accommodating weekly and monthly averages of jumps and leverage effects.

\section{Concluding Remarks}

The paper examined the impacts of co-jumps of two assets on forecasting co-volatility. We suggested disentangling the estimates of the integrated co-volatility matrix and jump variations so that they are positive (semi-) definite for coherence of the estimator. The empirical results for three stocks traded on the New York Stock Exchange showed that the co-jumps of any two assets have a significant impact on future co-volatility, but that the impact are minor in forecasting weekly and monthly horizons. The results also show that the impacts of the co-leverage effects caused by negative returns of two assets are significant, but the impact decreases for forecasting longer horizons.

The empirical evidence will be useful for improving forecasting models of the co-volatility matrix, as in Asai and McAleer (2014), who extended the work of Chiriac and Voev (2011) in order to accommodate factor specification, long memory and leverage effects. 


\section{References}

Aït-Sahalia, Y., and J. Jacod (2012), "Analyzing the Spectrum of Asset Returns: Jump and Volatility Components in High Frequency Data", Journal of Economic Literature, 50, 1007-1050.

Aït-Sahalia, Y., P.A. Mykland, and L. Zhang (2011), "Ultra High Frequency Volatility Estimation with Dependent Microstructure Noise", Journal of Econometrics, 160, 160-175.

Andersen, T.G., L. Benzoni, and J. Lund (2002), "An Empirical Investigation of Continuous-Time Equity Return Models", Journal of Finance, 57, 1239-1284.

Andersen, T.G., T. Bollerslev, and F.X. Diebold (2007), "Roughing It Up: Including Jump Components in the Measurement, Modeling and Forecasting of Return Volatility", Review of Economics and Statistics, 89, 701-720.

Andersen, T.G., D. Dobrev, and E. Schaumburg (2012), "Jump-Robust Volatility Estimation Using Nearest Neighbor Truncation", Journal of Econometrics, 169, 75-93.

Asai, M. and M. McAleer (2014), "Forecasting Co-Volatilities via Factor Models with Asymmetry and Long Memory in Realized Covariance", to appear in Journal of Econometrics.

Barndorff-Nielsen, O.E., P.R. Hansen, A. Lunde, and N. Shephard (2011), "Multivariate Realised Kernels: Consistent Positive Semi-Definite Estimators of The Covariation of Equity Prices with Noise and Non-Synchronous Trading", Journal of Econometrics, 162, 149-169.

Barndorff-Nielsen, O.E. and N. Shephard (2004a), "Power and Bipower Variation with Stochastic Volatility and Jumps", Journal of Financial Econometrics, 2, 1-37.

Barndorff-Nielsen, O. E., and N. Shephard (2004b), "Measuring the Impact of Jumps in Multivariate Price Processes Using Bipower Covariation", Discussion paper, Nuffield College, Oxford University.

Bates, D.S. (2000), "Post-' 87 Crash Fears in the S\&P 500 Futures Option Market", Journal of Econometrics, 94, 181-238.

Bickel, P. J., and E. Levina (2008a), "Regularized Estimation of Large Covariance Matrices", Annals of Statistics, 36, 199-277.

Bickel, P. J., and E. Levina (2008b), "Covariance Regularization by Thresholding", Annals of Statistics, 36, 2577-2604.

Bollerslev, T. and E. Ghysels (1996), "Periodic Autoregressive Conditional Heteroscedasticity", Journal of Business \& Economic Statistics, 14, 139-151.

Bollerslev, T., U. Kretschmer, C. Pigorsch, and G. Tauchen (2009), "A Discrete-Time Model for Daily S\&P500 Returns and Realized Variations: Jumps and Leverage Effects", Journal of Econometrics, 150, 151-166.

Boudt, K., J. Cornelissen, and S. Laurent (2012), "Jump Robust Daily Covariance Estimation by Disentangling Variance and Correlation Components", Computational Statistics and Data Analysis, 56, 2993-3005.

Boudt, K., C. Croux, and S. Laurent (2011), "Outlyingness Weighted Covariation", Journal of Financial Econometrics, 9, 657-684.

Boudt, K. and J. Zhang (2013), "Jump Robust Two Time Scale Covariance Estimation and Realized Volatility Budgets", to appear in Quantitative Finance.

Chernov, M., A.R. Gallant, E. Ghysels, and G. Tauchen (2003), "Alternative Models for Stock Price Dynamics", Journal of Econometrics, 116, 225-257.

Chiriac, R., and V. Voev (2011), "Modelling and Forecasting Multivariate Realized Volatility", Journal of Applied Econometrics, 26, 922-947. 
Corsi, F., D. Pirino, and R. Renó (2010), "Threshold Bipower Variation and The Impact of Jumps on Volatility Forecasting", Journal of Econometrics, 159, 276-288.

Diebold, F. and R. Mariano (1995), "Comparing Predictive Accuracy", Journal of Business \& Economic Statistics, 13, 253-263.

Eraker, B. (2004), "Do Stock Prices and Volatility Jump?: Reconciling Evidence from Spot and Option Prices", Journal of Finance, 59, 1367-1403.

Eraker, B., M. Johannes, and N. Polson (2003), "The Impact of Jumps in Volatility and Returns", Journal of Finance, 58, 1269-1300.

Hautsch, N. L.M. Kyj and R.C.A. Oomen (2012), "A Blocking and Regularization Approach to HighDimensional Realized Covariance Estimation", Journal of Applied Econometrics, 27, 625-645.

Huang, X., and G. Tauchen (2005), "The Relative Contribution of Jumps to Total Price Variance", Journal of Financial Econometrics, 3, 456-99.

Hayashi, T. and N. Yoshida (2005), "On Covariance Estimation of Nonsynchronously Observed Diffusion Processes," Bernoulli, 11, 359-379.

Kroner, K.F., and V.K. Ng. (1998), "Modeling Asymmetric Co-movements of Assets Returns", Review of Financial Studies, 11, 817-844.

Mancini, C., and R. Renó (2011), "Threshold Estimation of Jump-Diffusion Models and Interest Rate Modeling", Journal of Econometrics, 160, 77-92.

Pan, J. (2002), "The Jump-Risk Premia Implicit in Options: Evidence from an Integrated Time-Series Study", Journal of Financial Economics, 63, 3-50.

Tao, M., Y. Wang, Q. Yao and J. Zou (2011), "Large Volatility Matrix Inference via Combining LowFrequency and High-Frequency Approaches", Journal of the American Statistical Association, 106, $1025-1040$

Zhang, L. (2011), "Estimating Covariation: Epps Effect, Microstructure Noise", Journal of Econometrics, 160, 33-47.

Zhang, L., P.A. Mykland, and Y. Aït-Sahalia (2005), "A Tale of Two Time Scales: Determining Integrated Volatility with Noisy High-Frequency Data", Journal of American Statistical Association, 100, 13941411. 
Figure 1: Significant Jump Variability
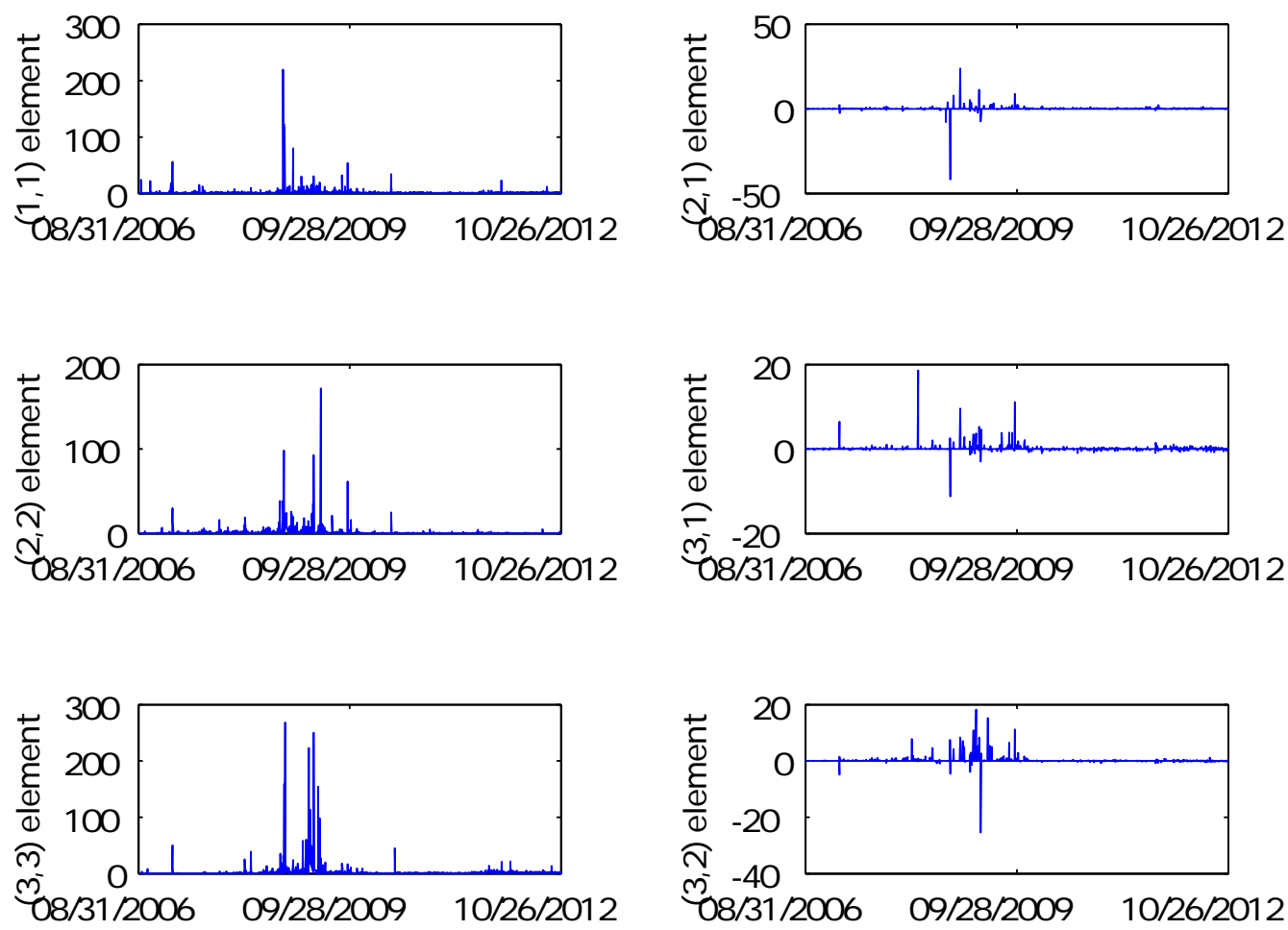

Note: Figure 1 shows the elements of the estimated jump variability, $\tilde{J}_{t}$. 
Table 1: Descriptive Statistics of Returns, Volatilities and Co-Volatilities

\begin{tabular}{l|rrrrr}
\hline \hline Stock & Mean & Std.Dev. & Skew. & Kurt. & Jump \\
\hline Return & & & & & \\
AA & -0.1774 & 2.5654 & -0.7776 & 8.5702 & 0.7427 \\
AXP & 0.0901 & 2.4974 & 0.2361 & 8.5106 & 0.6567 \\
BAC & -0.2423 & 3.6214 & -0.2525 & 13.054 & 0.7493 \\
Volatility & & & & & \\
AA & 8.7539 & 18.631 & 11.889 & 205.76 & 0.7427 \\
AXP & 7.1665 & 16.169 & 9.2182 & 142.78 & 0.6567 \\
BAC & 12.868 & 35.086 & 9.3138 & 132.06 & 0.7493 \\
Co-Volatility & & & & & \\
(AA,AXP) & 2.6239 & 5.7089 & 7.2000 & 85.797 & 0.1927 \\
(AA,BAC) & 1.8688 & 5.7782 & 6.1792 & 61.365 & 0.1567 \\
(AXP,BAC) & 2.4725 & 7.0694 & 5.1704 & 38.815 & 0.1653 \\
\hline \hline
\end{tabular}

Note: The sample period is from August 31, 2006 to October 26, 2012.

'Jump' denotes the percentage of occurrence of significant jumps. 
Table 2: In-sample Estimates for Daily Regressions

HAR $\quad \hat{\Omega}_{i j, t}=\beta_{0}+\beta_{d} \hat{\Omega}_{i j, t-1}+\beta_{w} \hat{\Omega}_{i j, t-5: t-1}+\beta_{m} \hat{\Omega}_{i j, t-22: t-1}+u_{i j, t}$

HAR-TCJ $\quad \hat{\Omega}_{i j, t}=\beta_{0}+\beta_{d} \tilde{C}_{i j, t-1}+\beta_{w} \tilde{C}_{i j, t-5: t-1}+\beta_{m} \tilde{C}_{i j, t-22: t-1}+\beta_{j} \tilde{J}_{i j, t-1}+u_{i j, t}$

HAR-TCJA $\quad \hat{\Omega}_{i j, t}=\beta_{0}+\beta_{d} \tilde{C}_{i j, t-1}+\beta_{w} \tilde{C}_{i j, t-5: t-1}+\beta_{m} \tilde{C}_{i j, t-22: t-1}+\beta_{j} \tilde{J}_{i j, t-1}+\beta_{a} r_{i, t-1}^{-} r_{j, t-1}^{-}+u_{i j, t}$

\begin{tabular}{|c|c|c|c|c|c|c|c|c|}
\hline Model & $\beta_{0}$ & $\beta_{d}$ & $\beta_{w}$ & $\beta_{m}$ & $\beta_{j}$ & $\beta_{a}$ & $R^{2}$ & $\bar{R}^{2}$ \\
\hline \multicolumn{9}{|c|}{ Volatility: AA } \\
\hline HAR & $\begin{array}{c}1.6711 \\
(0.0409)\end{array}$ & $\begin{array}{c}0.4550 \\
(0.0056)\end{array}$ & $\begin{array}{c}0.1287 \\
(0.0092)\end{array}$ & $\begin{array}{c}0.1038 \\
(0.0061)\end{array}$ & & & 0.6323 & 0.6300 \\
\hline HAR-TCJ & $\begin{array}{c}1.5831 \\
(0.0345)\end{array}$ & $\begin{array}{c}0.3690 \\
(0.0099)\end{array}$ & $\begin{array}{c}0.3930 \\
(0.0117)\end{array}$ & $\begin{array}{c}-0.0284 \\
(0.0065)\end{array}$ & $\begin{array}{c}0.4319 \\
(0.0076)\end{array}$ & & 0.6408 & 0.6378 \\
\hline HAR-TCJA & $\begin{array}{c}1.5658 \\
(0.0345)\end{array}$ & $\begin{array}{c}0.3211 \\
(0.0109)\end{array}$ & $\begin{array}{c}0.4144 \\
(0.0119)\end{array}$ & $\begin{array}{l}-0.0312 \\
(0.0065)\end{array}$ & $\begin{array}{c}0.4323 \\
(0.0077)\end{array}$ & $\begin{array}{c}0.0626 \\
(0.0023)\end{array}$ & 0.6436 & $0.6399^{\dagger}$ \\
\hline \multicolumn{9}{|c|}{ Volatility: AXP } \\
\hline HAR & $\begin{array}{c}0.6567 \\
(0.0175)\end{array}$ & $\begin{array}{c}0.4664 \\
(0.0066)\end{array}$ & $\begin{array}{c}0.3543 \\
(0.0083)\end{array}$ & $\begin{array}{c}0.0596 \\
(0.0048)\end{array}$ & & & 0.7723 & 0.7708 \\
\hline HAR-TCJ & $\begin{array}{c}0.7728 \\
(0.0172)\end{array}$ & $\begin{array}{c}0.4417 \\
(0.0085)\end{array}$ & $\begin{array}{c}0.4375 \\
(0.0107)\end{array}$ & $\begin{array}{c}0.0586 \\
(0.0057)\end{array}$ & $\begin{array}{c}0.3739 \\
(0.0090)\end{array}$ & & 0.7760 & 0.7741 \\
\hline HAR-TCJA & $\begin{array}{c}0.7092 \\
(0.0170)\end{array}$ & $\begin{array}{c}0.4436 \\
(0.0082)\end{array}$ & $\begin{array}{c}0.3964 \\
(0.0101)\end{array}$ & $\begin{array}{c}0.0573 \\
(0.0055)\end{array}$ & $\begin{array}{c}0.3539 \\
(0.0095)\end{array}$ & $\begin{array}{c}0.1293 \\
(0.0047)\end{array}$ & 0.7840 & $0.7817^{\dagger}$ \\
\hline \multicolumn{9}{|c|}{ Volatility: BAC } \\
\hline HAR & $\begin{array}{c}0.7184 \\
(0.0215)\end{array}$ & $\begin{array}{c}0.2631 \\
(0.0084)\end{array}$ & $\begin{array}{c}0.6070 \\
(0.0157)\end{array}$ & $\begin{array}{c}0.0072 \\
(0.0077)\end{array}$ & & & 0.6810 & 0.6790 \\
\hline HAR-TCJ & $\begin{array}{c}1.1223 \\
(0.0232)\end{array}$ & $\begin{array}{c}0.3888 \\
(0.0116)\end{array}$ & $\begin{array}{c}0.4806 \\
(0.0144)\end{array}$ & $\begin{array}{c}-0.0009 \\
(0.0067)\end{array}$ & $\begin{array}{c}0.1494 \\
(0.0059)\end{array}$ & & 0.6908 & 0.6882 \\
\hline HAR-TCJA & $\begin{array}{c}0.9580 \\
(0.0199)\end{array}$ & $\begin{array}{c}0.4396 \\
(0.0089)\end{array}$ & $\begin{array}{c}0.2622 \\
(0.0099)\end{array}$ & $\begin{array}{c}0.0464 \\
(0.0048)\end{array}$ & $\begin{array}{c}0.1674 \\
(0.0052)\end{array}$ & $\begin{array}{c}0.2937 \\
(0.0037)\end{array}$ & 0.7621 & $0.7596^{\dagger}$ \\
\hline \multicolumn{9}{|c|}{ Co-Volatility: AA-AXP } \\
\hline HAR & $\begin{array}{c}0.1846 \\
(0.0042)\end{array}$ & $\begin{array}{c}0.4377 \\
(0.0087)\end{array}$ & $\begin{array}{c}0.4079 \\
(0.0085)\end{array}$ & $\begin{array}{c}0.0110 \\
(0.0056)\end{array}$ & & & 0.7214 & 0.7196 \\
\hline HAR-TCJ & $\begin{array}{c}0.2329 \\
(0.0049)\end{array}$ & $\begin{array}{c}0.4086 \\
(0.0087)\end{array}$ & $\begin{array}{c}0.2683 \\
(0.0081)\end{array}$ & $\begin{array}{c}0.1688 \\
(0.0056)\end{array}$ & $\begin{array}{c}-0.1193 \\
(0.0164)\end{array}$ & & 0.7125 & 0.7101 \\
\hline HAR-TCJA & $\begin{array}{c}0.2067 \\
(0.0046)\end{array}$ & $\begin{array}{c}0.3954 \\
(0.0086)\end{array}$ & $\begin{array}{c}0.2637 \\
(0.0078)\end{array}$ & $\begin{array}{c}0.1596 \\
(0.0055)\end{array}$ & $\begin{array}{l}-0.1399 \\
(0.0167)\end{array}$ & $\begin{array}{c}0.0464 \\
(0.0019)\end{array}$ & 0.7223 & $0.7193^{\dagger}$ \\
\hline \multicolumn{9}{|c|}{ Co-Volatility: AA-BAC } \\
\hline HAR & $\begin{array}{c}0.2118 \\
(0.0049)\end{array}$ & $\begin{array}{c}0.3567 \\
(0.0130)\end{array}$ & $\begin{array}{c}0.2866 \\
(0.0107)\end{array}$ & $\begin{array}{c}0.1571 \\
(0.0078)\end{array}$ & & & 0.5211 & 0.5181 \\
\hline HAR-TCJ & $\begin{array}{c}0.2046 \\
(0.0042)\end{array}$ & $\begin{array}{c}0.5782 \\
(0.0106)\end{array}$ & $\begin{array}{c}0.0791 \\
(0.0115)\end{array}$ & $\begin{array}{c}0.3153 \\
(0.0084)\end{array}$ & $\begin{array}{c}0.0335 \\
(0.0037)\end{array}$ & & 0.5781 & 0.5746 \\
\hline HAR-TCJA & $\begin{array}{c}0.1716 \\
(0.0040)\end{array}$ & $\begin{array}{c}0.5607 \\
(0.0107)\end{array}$ & $\begin{array}{c}0.0703 \\
(0.0110)\end{array}$ & $\begin{array}{c}0.3095 \\
(0.0082)\end{array}$ & $\begin{array}{c}0.0340 \\
(0.0034)\end{array}$ & $\begin{array}{c}0.0544 \\
(0.0010)\end{array}$ & 0.5933 & $0.5890^{\dagger}$ \\
\hline \multicolumn{9}{|c|}{ Co-Volatility: AXP-BAC } \\
\hline HAR & $\begin{array}{c}0.2377 \\
(0.0088)\end{array}$ & $\begin{array}{c}0.5196 \\
(0.0139)\end{array}$ & $\begin{array}{c}0.2261 \\
(0.0092)\end{array}$ & $\begin{array}{c}0.1139 \\
(0.0052)\end{array}$ & & & 0.6544 & 0.6522 \\
\hline HAR-TCJ & $\begin{array}{c}0.0994 \\
(0.0075)\end{array}$ & $\begin{array}{c}0.6011 \\
(0.0096)\end{array}$ & $\begin{array}{c}0.2081 \\
(0.0098)\end{array}$ & $\begin{array}{c}0.2506 \\
(0.0070)\end{array}$ & $\begin{array}{c}0.3104 \\
(0.0177)\end{array}$ & & 0.6940 & 0.6914 \\
\hline HAR-TCJA & $\begin{array}{c}0.0122 \\
(0.0067)\end{array}$ & $\begin{array}{c}0.5693 \\
(0.0088)\end{array}$ & $\begin{array}{c}0.1691 \\
(0.0097)\end{array}$ & $\begin{array}{c}0.1904 \\
(0.0066)\end{array}$ & $\begin{array}{c}0.5108 \\
(0.0190)\end{array}$ & $\begin{array}{c}0.2180 \\
(0.0059)\end{array}$ & 0.7464 & $0.7437^{\dagger}$ \\
\hline
\end{tabular}

Note: Standard errors are given in parentheses. ' $\dagger$ ' denotes the model which has the highest $\bar{R}^{2}$ value of the three models. 
Table 3: Out-of-Sample Forecast Evaluation for Daily Regressions

\begin{tabular}{|c|c|c|c|c|c|c|}
\hline Model & $R^{2}$ & HRMSE & $J-R^{2}$ & $J$-HRMSE & $C-R^{2}$ & $C$-HRMSE \\
\hline \multicolumn{7}{|c|}{ Volatility: AA (783 Times Jump) } \\
\hline HAR & 0.3845 & 0.7304 & 0.3024 & 0.7613 & $0.7910^{\dagger}$ & 0.6061 \\
\hline HAR-TCJ & 0.4892 & $0.6264^{a}$ & 0.3390 & $0.6034^{a}$ & 0.7637 & 0.7032 \\
\hline HAR-TCJA & $0.5619^{\dagger}$ & $0.5958^{a}$ & $0.3992^{\dagger}$ & $0.5597^{a}$ & 0.7589 & 0.7112 \\
\hline \multicolumn{7}{|c|}{ Volatility: AXP (624 Times Jump) } \\
\hline HAR & 0.4958 & 1.0348 & 0.4552 & 1.1014 & 0.5755 & 0.9137 \\
\hline HAR-TCJ & 0.5300 & $0.8302^{a}$ & 0.4721 & $0.8209^{a}$ & $0.6208^{\dagger}$ & 0.8455 \\
\hline HAR-TCJA & $0.5462^{\dagger}$ & $0.7929^{a}$ & $0.4997^{\dagger}$ & $0.7678^{a}$ & 0.6205 & 0.8328 \\
\hline \multicolumn{7}{|c|}{ Volatility: BAC (782 Times Jump) } \\
\hline HAR & 0.5176 & 1.0610 & 0.5762 & 1.0914 & 0.5991 & 0.9440 \\
\hline HAR-TCJ & 0.5662 & $0.6276^{a}$ & $0.6185^{\dagger}$ & $0.6081^{a}$ & 0.5389 & 0.6933 \\
\hline HAR-TCJA & $0.5843^{\dagger}$ & $0.5894^{a}$ & 0.5981 & $0.5713^{a}$ & $0.6180^{\dagger}$ & 0.6503 \\
\hline \multicolumn{7}{|c|}{ Co-Volatility: AA-AXP (214 Times Co-Jump) } \\
\hline HAR & 0.5803 & 12.755 & $0.8817^{\dagger}$ & 2.8878 & 0.5665 & 14.308 \\
\hline HAR-TCJ & 0.6571 & 12.699 & 0.8634 & 3.1959 & 0.6508 & 14.226 \\
\hline HAR-TCJA & $0.7230^{\dagger}$ & 8.7809 & 0.6753 & 3.0606 & $0.7358^{\dagger}$ & 9.7748 \\
\hline \multicolumn{7}{|c|}{ Co-Volatility: AA-BAC (158 Times Co-Jump) } \\
\hline HAR & 0.6393 & 22.900 & 0.6792 & 8.5198 & 0.6369 & 24.681 \\
\hline HAR-TCJ & 0.6599 & 30.464 & 0.6308 & 9.0068 & 0.6622 & 32.969 \\
\hline HAR-TCJA & $0.6952^{\dagger}$ & 38.760 & $0.7551^{\dagger}$ & 5.9313 & $0.6970^{\dagger}$ & 42.162 \\
\hline \multicolumn{7}{|c|}{ Co-Volatility: AXP-BAC (162 Times Co-Jump) } \\
\hline HAR & $0.7184^{\dagger}$ & 28.174 & $0.7590^{\dagger}$ & 11.860 & $0.7158^{\dagger}$ & 30.333 \\
\hline HAR-TCJ & 0.7069 & 44.981 & 0.7408 & 16.458 & 0.7016 & 48.601 \\
\hline HAR-TCJA & 0.7023 & 39.962 & 0.7253 & 14.918 & 0.7037 & 43.159 \\
\hline \multicolumn{7}{|c|}{$\begin{array}{l}\text { Note: The table reports Mincer-Zarnowitz } R^{2} \text { and heteroskedasticity-adjusted root } \\
\text { mean squared error (HRMSE). } J-R^{2} \text { and } J \text {-HRMSE are } R^{2} \text { and HRMSE conditionally } \\
\text { on having a jump at time } t-1, \text { respectively, while } C-R^{2} \text { and } C \text {-HRMSE are conditional } \\
\text { on no jump at time } t-1 . ' \dagger \text { ' denotes the model which has the highest } R^{2} \text { value of the } \\
\text { three models. For the Diebold-Mariano test of equal forecast accuracy, ' } a \text { ', ' } b \text { ' and ' ' ' } \\
\text { denote significant improvements in forecasting performance with respect to the HAR, } \\
\text { HAR-TCJ and HAR-TCJA models, respectively. }\end{array}$} \\
\hline
\end{tabular}


Table 4: In-sample Estimates for Weekly Regressions

HAR $\quad \hat{\Omega}_{i j, t-5: t}=\beta_{0}+\beta_{d} \hat{\Omega}_{i j, t-1}+\beta_{w} \hat{\Omega}_{i j, t-5: t-1}+\beta_{m} \hat{\Omega}_{i j, t-22: t-1}+u_{i j, t}$

HAR-TCJ $\quad \hat{\Omega}_{i j, t-5: t}=\beta_{0}+\beta_{d} \tilde{C}_{i j, t-1}+\beta_{w} \tilde{C}_{i j, t-5: t-1}+\beta_{m} \tilde{C}_{i j, t-22: t-1}+\beta_{j} \tilde{J}_{i j, t-1}+u_{i j, t}$

HAR-TCJA $\quad \hat{\Omega}_{i j, t-5: t}=\beta_{0}+\beta_{d} \tilde{C}_{i j, t-1}+\beta_{w} \tilde{C}_{i j, t-5: t-1}+\beta_{m} \tilde{C}_{i j, t-22: t-1}+\beta_{j} \tilde{J}_{i j, t-1}+\beta_{a} r_{i, t-1}^{-} r_{j, t-1}^{-}+u_{i j, t}$

\begin{tabular}{|c|c|c|c|c|c|c|c|c|}
\hline Model & $\beta_{0}$ & $\beta_{d}$ & $\beta_{w}$ & $\beta_{m}$ & $\beta_{j}$ & $\beta_{a}$ & 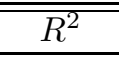 & 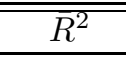 \\
\hline \multicolumn{9}{|c|}{ Volatility: AA } \\
\hline HAR & $\begin{array}{c}0.3697 \\
(0.0101)\end{array}$ & $\begin{array}{c}0.1609 \\
(0.0024)\end{array}$ & $\begin{array}{c}0.7982 \\
(0.0044)\end{array}$ & $\begin{array}{l}-0.0280 \\
(0.0023)\end{array}$ & & & 0.9643 & $0.9640^{\dagger}$ \\
\hline HAR-TCJ & $\begin{array}{c}0.9201 \\
(0.0152)\end{array}$ & $\begin{array}{c}0.1122 \\
(0.0039)\end{array}$ & $\begin{array}{c}0.9451 \\
(0.0060)\end{array}$ & $\begin{array}{l}-0.1670 \\
(0.0055)\end{array}$ & $\begin{array}{c}0.3723 \\
(0.0048)\end{array}$ & & 0.9208 & 0.9201 \\
\hline HAR-TCJA & $\begin{array}{c}0.9194 \\
(0.0153)\end{array}$ & $\begin{array}{c}0.1103 \\
(0.0041)\end{array}$ & $\begin{array}{c}0.9460 \\
(0.0060)\end{array}$ & $\begin{array}{l}-0.1671 \\
(0.0054)\end{array}$ & $\begin{array}{c}0.3723 \\
(0.0048)\end{array}$ & $\begin{array}{c}0.0025 \\
(0.0009)\end{array}$ & 0.9208 & 0.9200 \\
\hline \multicolumn{9}{|c|}{ Volatility: AXP } \\
\hline HAR & $\begin{array}{c}0.1517 \\
(0.0041)\end{array}$ & $\begin{array}{c}0.1768 \\
(0.0022)\end{array}$ & $\begin{array}{c}0.8207 \\
(0.0028)\end{array}$ & $\begin{array}{l}-0.0258 \\
(0.0013)\end{array}$ & & & 0.9822 & $0.9821^{\dagger}$ \\
\hline HAR-TCJ & $\begin{array}{c}0.3806 \\
(0.0081)\end{array}$ & $\begin{array}{c}0.1388 \\
(0.0028)\end{array}$ & $\begin{array}{c}0.8585 \\
(0.0056)\end{array}$ & $\begin{array}{c}0.0187 \\
(0.0026)\end{array}$ & $\begin{array}{c}0.3967 \\
(0.0049)\end{array}$ & & 0.9633 & 0.9630 \\
\hline HAR-TCJA & $\begin{array}{c}0.3664 \\
(0.0080)\end{array}$ & $\begin{array}{c}0.1392 \\
(0.0028)\end{array}$ & $\begin{array}{c}0.8493 \\
(0.0057)\end{array}$ & $\begin{array}{c}0.0184 \\
(0.0026)\end{array}$ & $\begin{array}{c}0.3923 \\
(0.0049)\end{array}$ & $\begin{array}{c}0.0288 \\
(0.0014)\end{array}$ & 0.9637 & 0.9634 \\
\hline \multicolumn{9}{|c|}{ Volatility: BAC } \\
\hline HAR & $\begin{array}{c}0.1706 \\
(0.0056)\end{array}$ & $\begin{array}{c}0.1270 \\
(0.0022)\end{array}$ & $\begin{array}{c}0.8772 \\
(0.0037)\end{array}$ & $\begin{array}{l}-0.0341 \\
(0.0018)\end{array}$ & & & 0.9749 & $0.9747^{\dagger}$ \\
\hline HAR-TCJ & $\begin{array}{c}0.6308 \\
(0.0116)\end{array}$ & $\begin{array}{c}0.1436 \\
(0.0032)\end{array}$ & $\begin{array}{c}0.8056 \\
(0.0055)\end{array}$ & $\begin{array}{l}-0.0182 \\
(0.0029)\end{array}$ & $\begin{array}{c}0.3145 \\
(0.0037)\end{array}$ & & 0.9493 & 0.9488 \\
\hline HAR-TCJA & $\begin{array}{c}0.5892 \\
(0.0108)\end{array}$ & $\begin{array}{c}0.1564 \\
(0.0029)\end{array}$ & $\begin{array}{c}0.7503 \\
(0.0052)\end{array}$ & $\begin{array}{l}-0.0063 \\
(0.0025)\end{array}$ & $\begin{array}{c}0.3191 \\
(0.0043)\end{array}$ & $\begin{array}{c}0.0743 \\
(0.0012)\end{array}$ & 0.9550 & 0.9545 \\
\hline \multicolumn{9}{|c|}{ Co-Volatility: AA-AXP } \\
\hline HAR & $\begin{array}{c}0.0413 \\
(0.0010)\end{array}$ & $\begin{array}{c}0.1796 \\
(0.0020)\end{array}$ & $\begin{array}{c}0.8257 \\
(0.0025)\end{array}$ & $\begin{array}{l}-0.0375 \\
(0.0014)\end{array}$ & & & 0.9799 & $0.9798^{\dagger}$ \\
\hline HAR-TCJ & $\begin{array}{c}0.1034 \\
(0.0023)\end{array}$ & $\begin{array}{c}0.1411 \\
(0.0039)\end{array}$ & $\begin{array}{c}0.6620 \\
(0.0042)\end{array}$ & $\begin{array}{c}0.1393 \\
(0.0027)\end{array}$ & $\begin{array}{c}0.1835 \\
(0.0061)\end{array}$ & & 0.9396 & 0.9391 \\
\hline HAR-TCJA & $\begin{array}{c}0.0905 \\
(0.0021)\end{array}$ & $\begin{array}{c}0.1347 \\
(0.0038)\end{array}$ & $\begin{array}{c}0.6596 \\
(0.0040)\end{array}$ & $\begin{array}{c}0.1346 \\
(0.0028)\end{array}$ & $\begin{array}{c}0.1780 \\
(0.0063)\end{array}$ & $\begin{array}{c}0.0229 \\
(0.0007)\end{array}$ & 0.9425 & 0.9419 \\
\hline \multicolumn{9}{|c|}{ Co-Volatility: AA-BAC } \\
\hline HAR & $\begin{array}{c}0.0488 \\
(0.0012)\end{array}$ & $\begin{array}{c}0.1384 \\
(0.0034)\end{array}$ & $\begin{array}{c}0.8252 \\
(0.0039)\end{array}$ & $\begin{array}{l}-0.0094 \\
(0.0022)\end{array}$ & & & 0.9529 & $0.9526^{\dagger}$ \\
\hline HAR-TCJ & $\begin{array}{c}0.1335 \\
(0.0025)\end{array}$ & $\begin{array}{c}0.1276 \\
(0.0048)\end{array}$ & $\begin{array}{c}0.7195 \\
(0.0061)\end{array}$ & $\begin{array}{c}0.1893 \\
(0.0043)\end{array}$ & $\begin{array}{c}0.2074 \\
(0.0012)\end{array}$ & & 0.8905 & 0.8895 \\
\hline HAR-TCJA & $\begin{array}{c}0.1166 \\
(0.0024)\end{array}$ & $\begin{array}{c}0.1186 \\
(0.0048)\end{array}$ & $\begin{array}{c}0.7151 \\
(0.0059)\end{array}$ & $\begin{array}{c}0.1864 \\
(0.0042)\end{array}$ & $\begin{array}{c}0.2077 \\
(0.0011)\end{array}$ & $\begin{array}{c}0.0278 \\
(0.0007)\end{array}$ & 0.8963 & 0.8952 \\
\hline \multicolumn{9}{|c|}{ Co-Volatility: AXP-BAC } \\
\hline HAR & $\begin{array}{c}0.0536 \\
(0.0021)\end{array}$ & $\begin{array}{c}0.1844 \\
(0.0030)\end{array}$ & $\begin{array}{c}0.8035 \\
(0.0029)\end{array}$ & $\begin{array}{l}-0.0197 \\
(0.0016)\end{array}$ & & & 0.9700 & $0.9699^{\dagger}$ \\
\hline HAR-TCJ & $\begin{array}{c}-0.0416 \\
(0.0038)\end{array}$ & $\begin{array}{c}0.1689 \\
(0.0042)\end{array}$ & $\begin{array}{c}0.7961 \\
(0.0091)\end{array}$ & $\begin{array}{c}0.1859 \\
(0.0039)\end{array}$ & $\begin{array}{c}0.3853 \\
(0.0095)\end{array}$ & & 0.9492 & 0.9488 \\
\hline HAR-TCJA & $\begin{array}{c}-0.0678 \\
(0.0036)\end{array}$ & $\begin{array}{c}0.1593 \\
(0.0040)\end{array}$ & $\begin{array}{c}0.7843 \\
(0.0091)\end{array}$ & $\begin{array}{c}0.1677 \\
(0.0037)\end{array}$ & $\begin{array}{c}0.4457 \\
(0.0089)\end{array}$ & $\begin{array}{c}0.0656 \\
(0.0016)\end{array}$ & 0.9553 & 0.9549 \\
\hline
\end{tabular}

Note: Standard errors are given in parentheses. ' $\dagger$ ' denotes the model which has the highest $\bar{R}^{2}$ value of the three models. 
Table 5: Out-of-Sample Forecast Evaluation for Weekly Regressions

\begin{tabular}{|c|c|c|c|c|c|c|}
\hline Model & $\overline{\mathrm{MZ} R^{2}}$ & HRMSE & $\bar{J}-R^{2}$ & $J$-HRMSE & $\overline{C-R^{2}}$ & $C$-HRMSE \\
\hline \multicolumn{7}{|c|}{ Volatility: AA (783 Times Jump) } \\
\hline HAR & 0.9228 & $0.1564^{b, c}$ & 0.9294 & $0.1555^{b, c}$ & 0.9281 & $0.1595^{b, c}$ \\
\hline HAR-TCJ & 0.9293 & 0.2015 & $0.9315^{\dagger}$ & 0.1930 & 0.9278 & 0.2296 \\
\hline HAR-TCJA & $0.9316^{\dagger}$ & 0.2010 & 0.9289 & 0.1915 & $0.9374^{\dagger}$ & 0.2322 \\
\hline \multicolumn{7}{|c|}{ Volatility: AXP (624 Times Jump) } \\
\hline HAR & $0.9432^{\dagger}$ & 0.2413 & $0.9469^{\dagger}$ & 0.2032 & $0.9375^{\dagger}$ & 0.2940 \\
\hline HAR-TCJ & 0.9367 & 0.2134 & 0.9400 & 0.1968 & 0.9323 & 0.2384 \\
\hline HAR-TCJA & 0.9344 & 0.2199 & 0.9379 & 0.2002 & 0.9293 & 0.2492 \\
\hline \multicolumn{7}{|c|}{ Volatility: BAC (782 Times Jump) } \\
\hline HAR & $0.9370^{\dagger}$ & $0.2234^{b, c}$ & $0.9490^{\dagger}$ & $0.2251^{b, c}$ & $0.8952^{\dagger}$ & $0.2171^{b, c}$ \\
\hline HAR-TCJ & 0.9302 & 0.2903 & 0.9398 & 0.2916 & 0.8801 & 0.2853 \\
\hline HAR-TCJA & 0.9300 & 0.3014 & 0.9367 & 0.3040 & 0.8951 & 0.2916 \\
\hline \multicolumn{7}{|c|}{ Co-Volatility: AA-AXP (214 Times Co-Jump) } \\
\hline HAR & 0.9612 & $0.2104^{b, c}$ & $0.9817^{\dagger}$ & $0.2090^{b, c}$ & 0.9594 & $0.2108^{b, c}$ \\
\hline HAR-TCJ & 0.9643 & 0.3024 & 0.9728 & 0.2950 & 0.9638 & 0.3044 \\
\hline HAR-TCJA & $0.9674^{\dagger}$ & 0.3007 & 0.9708 & 0.2869 & $0.9671^{\dagger}$ & 0.3044 \\
\hline \multicolumn{7}{|c|}{ Co-Volatility: AA-BAC (158 Times Co-Jump) } \\
\hline HAR & $0.9720^{\dagger}$ & 1593.4 & $0.9649^{\dagger}$ & 5.0064 & $0.9731^{\dagger}$ & 1736.5 \\
\hline HAR-TCJ & 0.9598 & 7538.7 & 0.9470 & 15.413 & 0.9613 & 8215.6 \\
\hline HAR-TCJA & 0.9625 & 6705.9 & 0.9492 & 14.383 & 0.9641 & 7308.0 \\
\hline \multicolumn{7}{|c|}{ Co-Volatility: AXP-BAC (162 Times Co-Jump) } \\
\hline HAR & $0.9798^{\dagger}$ & 26.029 & $0.9839^{\dagger}$ & 9.1612 & $0.9795^{\dagger}$ & 28.148 \\
\hline HAR-TCJ & 0.9559 & 67.683 & 0.9678 & 19.456 & 0.9534 & 73.440 \\
\hline HAR-TCJA & 0.9543 & 65.253 & 0.9607 & 18.689 & 0.9532 & 70.807 \\
\hline \multicolumn{7}{|c|}{$\begin{array}{l}\text { Note: The table reports Mincer-Zarnowitz } R^{2} \text { and heteroskedasticity-adjusted root } \\
\text { mean squared error (HRMSE). } J \text { - } R^{2} \text { and } J \text {-HRMSE are } R^{2} \text { and HRMSE conditionally } \\
\text { on having a jump at time } t-1 \text {, respectively, while } C-R^{2} \text { and } C \text {-HRMSE are conditional } \\
\text { on no jump at time } t-1 \text {. ' } \dagger \text { ' denotes the model which has the highest } R^{2} \text { value of the } \\
\text { three models. For the Diebold-Mariano test of equal forecast accuracy, ' } a \text { ', ' } b \text { ' and ' } c \text { ' } \\
\text { denote significant improvements in forecasting performance with respect to the HAR, } \\
\text { HAR-TCJ and HAR-TCJA models, respectively. }\end{array}$} \\
\hline
\end{tabular}


Table 6: In-sample Estimates for Monthly Regressions

HAR

$$
\hat{\Omega}_{i j, t-22: t}=\beta_{0}+\beta_{d} \hat{\Omega}_{i j, t-1}+\beta_{w} \hat{\Omega}_{i j, t-5: t-1}+\beta_{m} \hat{\Omega}_{i j, t-22: t-1}+u_{i j, t}
$$

HAR-TCJ $\quad \hat{\Omega}_{i j, t-22: t}=\beta_{0}+\beta_{d} \tilde{C}_{i j, t-1}+\beta_{w} \tilde{C}_{i j, t-5: t-1}+\beta_{m} \tilde{C}_{i j, t-22: t-1}+\beta_{j} \tilde{J}_{i j, t-1}+u_{i j, t}$

HAR-TCJA $\quad \hat{\Omega}_{i j, t-22: t}=\beta_{0}+\beta_{d} \tilde{C}_{i j, t-1}+\beta_{w} \tilde{C}_{i j, t-5: t-1}+\beta_{m} \tilde{C}_{i j, t-22: t-1}+\beta_{j} \tilde{J}_{i j, t-1}+\beta_{a} r_{i, t-1}^{-} r_{j, t-1}^{-}+u_{i j, t}$

\begin{tabular}{|c|c|c|c|c|c|c|c|c|}
\hline Model & $\beta_{0}$ & $\beta_{d}$ & $\beta_{w}$ & $\beta_{m}$ & $\beta_{j}$ & $\beta_{a}$ & $R^{2}$ & $\overline{R^{2}}$ \\
\hline \multicolumn{9}{|c|}{ Volatility: AA } \\
\hline HAR & $\begin{array}{c}0.0127 \\
(0.0023)\end{array}$ & $\begin{array}{c}0.0189 \\
(0.0003)\end{array}$ & $\begin{array}{c}0.0271 \\
(0.0007)\end{array}$ & $\begin{array}{c}0.9522 \\
(0.0007)\end{array}$ & & & 0.9971 & $0.9971^{\dagger}$ \\
\hline HAR-TCJ & $\begin{array}{c}0.9934 \\
(0.0141)\end{array}$ & $\begin{array}{l}-0.0040 \\
(0.0015)\end{array}$ & $\begin{array}{c}0.0593 \\
(0.0029)\end{array}$ & $\begin{array}{c}0.8911 \\
(0.0029)\end{array}$ & $\begin{array}{c}0.0884 \\
(0.0012)\end{array}$ & & 0.9664 & 0.9661 \\
\hline HAR-TCJA & $\begin{array}{c}0.9950 \\
(0.0150)\end{array}$ & $\begin{array}{c}0.0005 \\
(0.0014)\end{array}$ & $\begin{array}{c}0.0573 \\
(0.0029)\end{array}$ & $\begin{array}{c}0.8914 \\
(0.0030)\end{array}$ & $\begin{array}{c}0.0883 \\
(0.0012)\end{array}$ & $\begin{array}{l}-0.0058 \\
(0.0003)\end{array}$ & 0.9665 & 0.9661 \\
\hline \multicolumn{9}{|c|}{ Volatility: AXP } \\
\hline HAR & $\begin{array}{l}-0.0036 \\
(0.0011)\end{array}$ & $\begin{array}{c}0.0167 \\
(0.0003)\end{array}$ & $\begin{array}{c}0.0440 \\
(0.0006)\end{array}$ & $\begin{array}{c}0.9417 \\
(0.0006)\end{array}$ & & & 0.9985 & $0.9985^{\dagger}$ \\
\hline HAR-TCJ & $\begin{array}{c}0.3965 \\
(0.0071)\end{array}$ & $\begin{array}{c}0.0082 \\
(0.0010)\end{array}$ & $\begin{array}{c}0.0310 \\
(0.0021)\end{array}$ & $\begin{array}{c}1.0466 \\
(0.0026)\end{array}$ & $\begin{array}{c}0.0733 \\
(0.0010)\end{array}$ & & 0.9889 & 0.9888 \\
\hline HAR-TCJA & $\begin{array}{c}0.3956 \\
(0.0071)\end{array}$ & $\begin{array}{c}0.0082 \\
(0.0010)\end{array}$ & $\begin{array}{c}0.0305 \\
(0.0021)\end{array}$ & $\begin{array}{c}1.0466 \\
(0.0026)\end{array}$ & $\begin{array}{c}0.0731 \\
(0.0010)\end{array}$ & $\begin{array}{c}0.0018 \\
(0.0003)\end{array}$ & 0.9889 & 0.9888 \\
\hline \multicolumn{9}{|c|}{ Volatility: BAC } \\
\hline HAR & $\begin{array}{l}-0.0045 \\
(0.0015)\end{array}$ & $\begin{array}{c}0.0065 \\
(0.0004)\end{array}$ & $\begin{array}{c}0.0624 \\
(0.0009)\end{array}$ & $\begin{array}{c}0.9341 \\
(0.0008)\end{array}$ & & & 0.9980 & $0.9980^{\dagger}$ \\
\hline HAR-TCJ & $\begin{array}{c}0.5599 \\
(0.0077)\end{array}$ & $\begin{array}{c}0.0101 \\
(0.0009)\end{array}$ & $\begin{array}{c}0.0878 \\
(0.0019)\end{array}$ & $\begin{array}{c}0.8924 \\
(0.0017)\end{array}$ & $\begin{array}{c}0.0550 \\
(0.0005)\end{array}$ & & 0.9884 & 0.9883 \\
\hline HAR-TCJA & $\begin{array}{c}0.5497 \\
(0.0076)\end{array}$ & $\begin{array}{c}0.0133 \\
(0.0009)\end{array}$ & $\begin{array}{c}0.0742 \\
(0.0018)\end{array}$ & $\begin{array}{c}0.8953 \\
(0.0017)\end{array}$ & $\begin{array}{c}0.0562 \\
(0.0006)\end{array}$ & $\begin{array}{c}0.0183 \\
(0.0003)\end{array}$ & 0.9888 & 0.9887 \\
\hline \multicolumn{9}{|c|}{ Co-Volatility: AA-AXP } \\
\hline HAR & $\begin{array}{l}-0.0016 \\
(0.0002)\end{array}$ & $\begin{array}{c}0.0156 \\
(0.0004)\end{array}$ & $\begin{array}{c}0.0483 \\
(0.0006)\end{array}$ & $\begin{array}{c}0.9385 \\
(0.0007)\end{array}$ & & & 0.9981 & $0.9981^{\dagger}$ \\
\hline HAR-TCJ & $\begin{array}{c}0.0629 \\
(0.0015)\end{array}$ & $\begin{array}{c}0.0202 \\
(0.0012)\end{array}$ & $\begin{array}{c}0.0141 \\
(0.0023)\end{array}$ & $\begin{array}{c}0.9419 \\
(0.0023)\end{array}$ & $\begin{array}{c}0.0353 \\
(0.0022)\end{array}$ & & 0.9833 & 0.9831 \\
\hline HAR-TCJA & $\begin{array}{c}0.0598 \\
(0.0014)\end{array}$ & $\begin{array}{c}0.0187 \\
(0.0012)\end{array}$ & $\begin{array}{c}0.0135 \\
(0.0023)\end{array}$ & $\begin{array}{c}0.9408 \\
(0.0023)\end{array}$ & $\begin{array}{c}0.0340 \\
(0.0022)\end{array}$ & $\begin{array}{c}0.0054 \\
(0.0002)\end{array}$ & 0.9835 & 0.9833 \\
\hline \multicolumn{9}{|c|}{ Co-Volatility: AA-BAC } \\
\hline HAR & $\begin{array}{l}-0.0002 \\
(0.0004)\end{array}$ & $\begin{array}{c}0.0115 \\
(0.0008)\end{array}$ & $\begin{array}{c}0.0384 \\
(0.0008)\end{array}$ & $\begin{array}{c}0.9502 \\
(0.0007)\end{array}$ & & & 0.9961 & $0.9961^{\dagger}$ \\
\hline HAR-TCJ & $\begin{array}{c}0.2034 \\
(0.0033)\end{array}$ & $\begin{array}{c}0.0012 \\
(0.0018)\end{array}$ & $\begin{array}{c}-0.0790 \\
(0.0036)\end{array}$ & $\begin{array}{c}1.0513 \\
(0.0037)\end{array}$ & $\begin{array}{c}0.0413 \\
(0.0005)\end{array}$ & & 0.9486 & 0.9481 \\
\hline HAR-TCJA & $\begin{array}{c}0.1992 \\
(0.0033)\end{array}$ & $\begin{array}{l}-0.0010 \\
(0.0018)\end{array}$ & $\begin{array}{l}-0.0801 \\
(0.0036)\end{array}$ & $\begin{array}{c}1.0506 \\
(0.0037)\end{array}$ & $\begin{array}{c}0.0414 \\
(0.0005)\end{array}$ & $\begin{array}{c}0.0069 \\
(0.0004)\end{array}$ & 0.9490 & 0.9485 \\
\hline \multicolumn{9}{|c|}{ Co-Volatility: AXP-BAC } \\
\hline HAR & $\begin{array}{c}-0.0037 \\
(0.0005)\end{array}$ & $\begin{array}{c}0.0203 \\
(0.0006)\end{array}$ & $\begin{array}{c}0.0355 \\
(0.0007)\end{array}$ & $\begin{array}{c}0.9462 \\
(0.0007)\end{array}$ & & & 0.9973 & $0.9973^{\dagger}$ \\
\hline HAR-TCJ & $\begin{array}{c}0.0064 \\
(0.0028)\end{array}$ & $\begin{array}{c}0.0144 \\
(0.0012)\end{array}$ & $\begin{array}{c}-0.0502 \\
(0.0032)\end{array}$ & $\begin{array}{c}1.1736 \\
(0.0050)\end{array}$ & $\begin{array}{c}0.0516 \\
(0.0033)\end{array}$ & & 0.9797 & 0.9796 \\
\hline HAR-TCJA & $\begin{array}{c}0.0006 \\
(0.0027)\end{array}$ & $\begin{array}{c}0.0122 \\
(0.0013)\end{array}$ & $\begin{array}{l}-0.0529 \\
(0.0031)\end{array}$ & $\begin{array}{c}1.1695 \\
(0.0050)\end{array}$ & $\begin{array}{c}0.0651 \\
(0.0032)\end{array}$ & $\begin{array}{c}0.0147 \\
(0.0005)\end{array}$ & 0.9801 & 0.9799 \\
\hline
\end{tabular}

Note: Standard errors are given in parentheses. ' $\uparrow$ ' denotes the model which has the highest $\bar{R}^{2}$ value of the three models. 
Table 7: Out-of-Sample Forecast Evaluation for Monthly Regressions

\begin{tabular}{|c|c|c|c|c|c|c|}
\hline$\overline{\text { Model }}$ & $\overline{\mathrm{MZ} R^{2}}$ & HRMSE & $J-R^{2}$ & $J$-HRMSE & $\overline{C C-R^{2}}$ & $\overline{C-\mathrm{HRMSE}}$ \\
\hline \multicolumn{7}{|c|}{ Volatility: AA (783 Times Jump) } \\
\hline HAR & $0.9948^{\dagger}$ & $0.0439^{b, c}$ & $0.9933^{\dagger}$ & $0.0437^{b, c}$ & 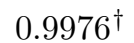 & $0.0446^{b, c}$ \\
\hline HAR-TCJ & 0.9852 & 0.1496 & 0.9855 & 0.1516 & 0.9848 & 0.1421 \\
\hline HAR-TCJA & 0.9854 & 0.1495 & 0.9848 & 0.1516 & 0.9866 & 0.1417 \\
\hline \multicolumn{7}{|c|}{ Volatility: AXP (624 Times Jump) } \\
\hline HAR & $0.9964^{\dagger}$ & $0.0526^{b, c}$ & $0.9958^{\dagger}$ & $0.0519^{b, c}$ & $0.9975^{\dagger}$ & $0.0538^{b, c}$ \\
\hline HAR-TCJ & 0.9892 & 0.1180 & 0.9875 & 0.1165 & 0.9922 & 0.1205 \\
\hline HAR-TCJA & 0.9889 & 0.1192 & 0.9873 & 0.1174 & 0.9918 & 0.1221 \\
\hline \multicolumn{7}{|c|}{ Volatility: BAC (782 Times Jump) } \\
\hline HAR & $0.9958^{\dagger}$ & $0.0494^{b, c}$ & $0.9975^{\dagger}$ & $0.0453^{b, c}$ & $0.9861^{\dagger}$ & $0.0619^{b, c}$ \\
\hline HAR-TCJ & 0.9850 & 0.1747 & 0.9877 & 0.1729 & 0.9726 & 0.1809 \\
\hline HAR-TCJA & 0.9849 & 0.1749 & 0.9874 & 0.1734 & 0.9735 & 0.1800 \\
\hline \multicolumn{7}{|c|}{ Co-Volatility: AA-AXP (214 Times Co-Jump) } \\
\hline HAR & $0.9976^{\dagger}$ & $0.0490^{b, c}$ & $0.9994^{\dagger}$ & $0.0398^{b, c}$ & $0.9974^{\dagger}$ & $0.0512^{b, c}$ \\
\hline HAR-TCJ & 0.9964 & 0.1514 & 0.9967 & 0.1667 & 0.9964 & 0.1469 \\
\hline HAR-TCJA & 0.9965 & 0.1511 & 0.9965 & 0.1665 & 0.9965 & 0.1466 \\
\hline \multicolumn{7}{|c|}{ Co-Volatility: AA-BAC (158 Times Co-Jump) } \\
\hline HAR & $0.9976^{\dagger}$ & 8.6145 & $0.9972^{\dagger}$ & 1.1431 & $0.9977^{\dagger}$ & 9.3749 \\
\hline HAR-TCJ & 0.9930 & 86.071 & 0.9946 & 13.894 & 0.9928 & 93.606 \\
\hline HAR-TCJA & 0.9932 & 83.126 & 0.9945 & 13.515 & 0.9931 & 90.401 \\
\hline \multicolumn{7}{|c|}{ Co-Volatility: AXP-BAC (162 Times Co-Jump) } \\
\hline HAR & $0.9982^{\dagger}$ & 12.108 & $0.9984^{\dagger}$ & 2.2816 & $0.9981^{\dagger}$ & 13.189 \\
\hline HAR-TCJ & 0.9910 & 187.73 & 0.9895 & 12.910 & 0.9914 & 204.99 \\
\hline HAR-TCJA & 0.9909 & 187.37 & 0.9895 & 12.839 & 0.9912 & 204.60 \\
\hline \multicolumn{7}{|c|}{$\begin{array}{l}\text { Note: The table reports Mincer-Zarnowitz } R^{2} \text { and heteroskedasticity-adjusted root } \\
\text { mean squared error (HRMSE). } J \text { - } R^{2} \text { and } J \text {-HRMSE are } R^{2} \text { and HRMSE conditionally } \\
\text { on having a jump at time } t-1, \text { respectively, while } C-R^{2} \text { and } C \text {-HRMSE are conditional } \\
\text { on no jump at time } t-1 \text {. ' } \dagger \text { ' denotes the model which has the highest } R^{2} \text { value of the } \\
\text { three models. For the Diebold-Mariano test of equal forecast accuracy, ' } a \text { ', ' } b \text { ' and ' } c \text { ' } \\
\text { denote significant improvements in forecasting performance with respect to the HAR, } \\
\text { HAR-TCJ and HAR-TCJA models, respectively. }\end{array}$} \\
\hline
\end{tabular}

